\title{
COPD in women: susceptibility or vulnerability?
}

\author{
Raúl H. Sansores and Alejandra Ramírez-Venegas \\ Affiliation: Departamento de Investigación en Tabaquismo y EPOC, Instituto Nacional de Enfermedades
} Respiratorias, Ismael Cosio Villegas, Mexico City, Mexico.

Correspondence: Raúl H. Sansores, Instituto Nacional de Enfermedades Respiratorias, Ismael Cosio Villegas, Departamento de Investigación en Tabaquismo y EPOC, Calzada de Tlalpan 4502, Seccion XVI, 14080 Mexico City, Mexico. E-mail: raulsansoresđyahoo.com.mx

0

$@$ ERSpublications

Women are both more susceptible and more vulnerable than men when it comes to COPD http://ow.ly/UhMQ3

The concepts of susceptibility and vulnerability are intertwined because vulnerability is sometimes a consequence of being susceptible. Women are more likely to be susceptible to chronic obstructive pulmonary disease (COPD) than men [1]. As many women continue to smoke during pregnancy, the impact of tobacco in women can begin before birth [2], because maternal smoking during pregnancy may increase the risk of childhood respiratory diseases [3] and reduce lung function [2]. Indeed, this susceptibility starts before women become smokers. For example, women with specific genotype variants are at a significantly increased risk of becoming heavy smokers [4], while those women with the haplotype TAS2R38 (proline-alanine-valine) have a genetic propensity to experience heightened bitter taste perception and an increased preference for menthol cigarettes [5]. Recent findings of the Global Youth Tobacco survey on adolescents aged 13-15 years showed that young girls smoke as much as young boys [6]. The early onset of smoking may have a greater deleterious impact on lung function among girls [7] because their lungs are smaller than those of males. Accordingly, the same exposure to a given number of cigarettes smoked can lead to more deleterious effects in women [8]. In this regard, once young females become smokers, addiction may be reinforced by both nicotine and the sensory and social contexts of smoking. Motivations associated with gender can provoke women to have different cues for smoking compared with males [9]; therefore, women are more vulnerable to the social context of smoking and can easily become involved in the nicotine addictive process, along with consequent disease risks.

However, the risk for COPD in women has been associated with both gender and sex biology. For instance, biomass exposure associated to COPD has been linked to gender [10] and the levels of oestrogen [8], and thus to sex biology, as in tobacco smoking. Sex differences associated with oestrogen trigger a search for femininity and body image in young women, and this search is exploited by tobacco companies. These companies sponsor promotions in which public smoking is portrayed by attractive models and movie stars to associate tobacco use with glamour, which more easily targets young women [11]. In young women, oestrogen induces lung differentiation and maturation [8]. However, by the age of menopause, levels of oestrogen and progesterone decline, and there is an important loss of lung function and reduced forced expiratory volume in $1 \mathrm{~s}$ (FEV1) that are associated with smoking [8].

Approximately $20 \%$ of the smoking population worldwide are women [6]. This estimate has modified overall vital statistics by increasing the COPD prevalence for women and increasing the frequency of deaths due to COPD [12, 13]. A recent analysis of mortality across three time-periods (1959-1965, 1982-1988 and 2000-2010) showed that the risk of death from cigarette smoking has continually increased among women [14], and the relative risk of death from COPD is now nearly identical for men and women (relative risk of 25 and 27.8 for women and men, respectively) [15].

Received: Oct 282015 | Accepted: Oct 302015

Conflict of interest: None declared.

Copyright OERS 2016 
The similar mortality rate among men and women can be explained by a rapid deterioration of women once they begin smoking, suggesting a differential propensity for the damaging effects of tobacco smoke. For example, although cross-sectional studies have shown that, at all stages of COPD severity, men have more emphysema than women, as measured by computed tomography (CT) scan [16], the annual decline in lung density (emphysema) is more rapid in women [17]. Similarly, Prescott et al. [18] estimated the effects of smoking on lung function and consistently detected greater loss of FEV1 per pack-year of smoking in women compared with men. Similarly, a more recent meta-analysis of the annual rate of decline in FEV1 in men and women showed that female current smokers had, with increasing age, a significantly faster annual decline in per cent predicted FEV1 compared with male current smokers [19]. Both the greater velocity of the FEV1 decline and worsening emphysema have clinical consequences. In the PLATINO (Proyecto Latinoamericano de Investigación en Obstrucción Pulmonar) study [20], currently smoking females with COPD had more severe obstruction compared with males who had similar cigarette exposure. However, when comparing the sexes among subjects with COPD, females smoked less than males, but $63 \%$ of women compared with $44 \%$ of males reported a modified Medical Research Council dyspnoea score $\geqslant 2$. Additionally, a general health status report of fair-to-poor was significantly more common in women. A poorer quality of life has been reported more frequently in females than in males with COPD [21], along with more hospitalisations [18] and exacerbations despite having a similar FEV1, better oxygenation, better arterial carbon dioxide tension and fewer comorbidities [22].

In 1998, in a study of the epidemiology and genetics of cases with severe, early-onset COPD without severe $\alpha_{1}$-antitrypsin deficiency, SILVERMAN et al. [1] detected an unexpected prevalence of $79.6 \%$ for females. 2 years later, by expanding their sample size from 44 original families to 84 early-onset COPD families, the researchers showed that first-degree female relatives were more likely to have a $>40 \%$ reduction in FEV1 than first-degree male smoking relatives, which suggested that women may be more susceptible to developing severe COPD [23]. More recently, a study by Foreman et al. [24] re-defined severe, early-onset $\mathrm{COPD}$ as a $\mathrm{FEV} 1 /$ forced vital capacity ratio $<0.70$ and $\mathrm{FEV} 1$ postbronchodilator $<50 \%$ in subjects $<55$ years of age, and enrolled 70 subjects. Among these subjects, $66 \%$ were women. Notably, the group with severe, early-onset COPD, compared with older subjects with COPD, had significantly less cumulative tobacco exposure measured as pack-years of smoking. This finding suggests that tobacco smoking was not a primary factor for the development of early-onset COPD and that additional factors were also involved. These factors were mainly sex linked, such as genetic determinants, maternal factors and their interactions, which may explain both the appearance of severe, early-onset COPD as well as the onset of smoking and consequent development of COPD in females.

The study by HARDIN et al. [25] in the current issue of the European Respiratory Journal highlights once again the greater susceptibility of women to the development of COPD. Additionally, convincing findings demonstrated that women with severe emphysema and severe, early-onset COPD and women with Global Initiative for Chronic Obstructive Lung Disease (GOLD) grade IV exhibited similar rates of emphysema to men but were associated with markedly fewer pack-years, illustrating the following aspects of COPD that warrant further study: 1) the advantages and benefits of phenotyping COPD patients; 2) the need for strategies other than FEV1 to make a diagnosis of COPD; 3) the perspective of gender regarding the public health phenomenon of COPD; and 4) the need for early diagnosis of COPD in smokers, particularly in women smokers, to prevent the late consequences of severe COPD.

HARDIN et al. [25] describe at least three phenotypes (early onset COPD, severe emphysema and GOLD grade IV COPD) and suggest the previously reported radiographic emphysema phenotype. According to the work of TATSUMi et al. [26], 90\% of subjects with COPD have an emphysema-dominant phenotype. Therefore, considering that asymptomatic smokers with COPD have been previously described in subjects with emphysema using lung imaging [27], CT may become the only strategy to detect early COPD. Therefore, although females have an airway disease-dominant phenotype [26, 28], the data of HARDIN et al. [25] show that women with early-onset COPD have equivalent emphysema with fewer pack-years of smoking, which should motivate us to incorporate the gender perspective and need for early diagnosis into our clinical practice. Gender selection for the development of COPD may be enhanced by disadvantages encountered during childhood [3, 29].

The study of HARDIN et al. [25] also yields insights into which currently used instruments other than FEV1 should be used to make an early diagnosis and evaluate the severity of COPD. Other investigators who have analysed the progression of COPD have found that FEV1 is an inconsistent measurement [30] and that the rate of change can be highly variable [31], so it is not a good overall measure of the processes that lead to COPD [32] and is poorly related to mortality [30]. The use of CT as a screening strategy may detect women at risk and aid in the early diagnosis of severe, early-onset COPD. However, this approach may not be cost-effective. Nevertheless, it reminds us of the need for new and less expensive tools for the detection of COPD because emphysema may appear before FEV1 declines. HARDIN et al. [25] highlight the 
dilemma of the early onset of severe COPD when no strategies exist to make an early diagnosis of COPD in these women, which is even more problematic if they had been asymptomatic smokers.

When reading this article on women $<50$ years of age with FEV $1<50 \%$ and similar degrees of emphysema to men, we posit the following open questions. When is this damage initiated? What can we do to prevent it? What can we do to make an earlier diagnosis? Why do women who have the same or lower magnitude of tobacco exposure as men develop more severe airflow limitation and emphysema?

These questions may have been difficult to address and, independently of the reflections of the authors, their results appear to give a dual answer: women are both more susceptible and more vulnerable than men. Understanding the genetic, molecular, social and behavioural mechanisms that underlie these differences will require further research. The extent to which both susceptibility and vulnerability contribute and interact to explain sex and gender differences for COPD development and its severity is also largely unexplored. This paper by HARDIN et al. [25] represents an important step towards understanding these important issues.

\section{References}

1 Silverman EK, Chapman HA, Drazen JM, et al. Genetic epidemiology of severe, early-onset chronic obstructive pulmonary disease. Risk to relatives for airflow obstruction and chronic bronchitis. Am J Respir Crit Care Med 1998; 157: 1770-1778.

2 Leslie FM. Multigenerational epigenetic effects of nicotine on lung function. BMC Med 2013; 11: 27.

3 Li YF, Langholz B, Salam MT, et al. Maternal and grandmaternal smoking patterns are associated with early childhood asthma. Chest 2005; 127: 1232-1241.

4 Conlon MS, Bewick MA. Single nucleotide polymorphisms in CHRNA5 rs16969968, CHRNA3 rs578776, and LOC123688 rs8034191 are associated with heaviness of smoking in women in Northeastern Ontario, Canada. Nicotine Tob Res 2011; 13: 1076-1083.

5 Oncken C, Feinn R, Covault J, et al. Genetic vulnerability to menthol cigarette preference in women. Nicotine Tob Res 2015; 17: 1416-1420.

6 Gender, Health and Tobacco. Geneva, World Health Organization, 2003. www.who.int/gender/documents/ Gender_Tobacco_2.pdf?ua=1

7 Langhammer A, Johnsen R, Gulsvik A, et al. Sex differences in lung vulnerability to tobacco smoking. Eur Respir J 2003; 21: 1017-1023.

8 Mustonen TK, Spencer SM, Hoskinson RA, et al. The influence of gender, race, and menthol content on tobacco exposure measures. Nicotine Tob Res 2005; 7: 581-590.

9 Greaves LJ, Richardson LA. Tobacco use, women, gender, and chronic obstructive pulmonary disease: are the connections being adequately made? Proc Am Thorac Soc 2007; 4: 675-679.

10 Ramírez-Venegas A, Sansores RH, Velázquez-Uncal M, et al. Nonsmokers and biomass exposure. In: Anzueto A, Heijdra Y, Hurst JR, eds. Controversies in COPD (ERS Monograph). Sheffield, European Respiratory Society, 2015; pp. 35-46.

11 Samet JM, Yoon SY, eds. Gender, Women and the Tobacco Epidemic. Geneva, World Health Organization, 2010.

12 Kamil F, Pinzon I, Foreman MG. Sex and race factors in early-onset COPD. Curr Opin Pulm Med 2013; 19: $140-144$.

13 Mannino DM, Homa DM, Akinbami LJ, et al. Chronic obstructive pulmonary disease surveillance - United States, 1971-2000. MMWR Surveill Summ 2002; 51: 1-16.

14 Thun MJ, Carter BD, Feskanich D, et al. 50-year trends in smoking-related mortality in the United States. $N$ Engl J Med 2013; 368: 351-364.

15 Carter BD, Abnet CC, Feskanich D, et al. Smoking and mortality - beyond established causes. N Engl J Med 2015; 372: 631-640.

16 Dransfield MT, Washko GR, Foreman MG, et al. Gender differences in the severity of CT emphysema in COPD. Chest 2007; 132: 464-470.

17 Coxson HO, Dirksen A, Edwards LD, et al. The presence and progression of emphysema in COPD as determined by CT scanning and biomarker expression: a prospective analysis from the ECLIPSE study. Lancet Respir Med 2013; 1: 129-136.

18 Prescott E, Bjerg AM, Andersen PK, et al. Gender difference in smoking effects on lung function and risk of hospitalization for COPD: results from a Danish longitudinal population study. Eur Respir J 1997; 10: 822-827.

19 Gan WQ, Man SF, Postma DS, et al. Female smokers beyond the perimenopausal period are at increased risk of chronic obstructive pulmonary disease: a systematic review and meta-analysis. Respir Res 2006; 7: 52.

20 Lopez Varela MV, Montes de Oca M, Halbert RJ, et al. Sex-related differences in COPD in five Latin American cities: the PLATINO study. Eur Respir J 2010; 36: 1034-1041.

21 de Torres JP, Casanova C, Hernández C, et al. Gender associated differences in determinants of quality of life in patients with COPD: a case series study. Health Qual Life Outcomes 2006; 4: 72.

22 de Torres JP, Casanova C, Hernández C, et al. Gender and COPD in patients attending a pulmonary clinic. Chest 2005; 128: 2012-2016.

23 Silverman EK, Weiss ST, Drazen JM, et al. Gender-related differences in severe, early-onset chronic obstructive pulmonary disease. Am J Respir Crit Care Med 2000; 162: 2152-2158.

24 Foreman MG, Zhang L, Murphy J, et al. Early-onset chronic obstructive pulmonary disease is associated with female sex, maternal factors, and African American race in the COPDGene Study. Am J Respir Crit Care Med 2011; 184: 414-420.

25 Hardin M, Foreman M, Dransfield MT, et al. Sex-specific features of emphysema among current and former smokers with COPD. Eur Respir J 2016; 47: 104-112.

26 Tatsumi K, Kasahara Y, Kurosu K, et al. Clinical phenotypes of COPD: results of a Japanese epidemiological survey. Respirology 2004; 9: 331-336. 
27 Yasunaga K, Chérot-Kornobis N, Edmé JL, et al. Emphysema in asymptomatic smokers: quantitative CT evaluation in correlation with pulmonary function tests. Diagn Interv Imaging 2013; 94: 609-617.

28 Camp PG, Ramirez-Venegas A, Sansores RH, et al. COPD phenotypes in biomass smoke- versus tobacco smoke-exposed Mexican women. Eur Respir J 2014; 43: 725-734.

29 Svanes C, Sunyer J, Plana E, et al. Early life origins of chronic obstructive pulmonary disease. Thorax 2010; 65: $14-20$.

30 Casanova C, Aguirre-Jaíme A, de Torres JP, et al. Longitudinal assessment in COPD patients: multidimensional variability and outcomes. Eur Respir J 2014; 43: 745-753.

31 Vestbo J, Edwards LD, Scanlon PD, et al. Changes in forced expiratory volume in 1 second over time in COPD. N Engl J Med 2011; 365: 1184-1192.

32 Vestbo J, Lange P. Re-assessing the importance of FEVı decline. In: Anzueto A, Heijdra Y, Hurst JR, eds. Controversies in COPD (ERS Monograph). Sheffield, European Respiratory Society, 2015; pp. 134-142. 